\section{Questión}

Periodismo / Comunicación ISSN 1669.6581

Periodismo de memes y memes en el periodismo

Claudio Avilés Rodilla

Question/Cuestión, Nro.70, Vol.3, diciembre 2021

ISSN: 1669-6581

URL de la Revista: https://perio.unlp.edu.ar/ojs/index.php/question/

IICom -FPyCS -UNLP

DOI: https//doi.org/10.24215/16696581e639

\title{
Periodismo de memes y memes en el periodismo
}

\section{Journalism of memes and memes in journalism}

Claudio Avilés Rodilla

Universidad Nacional de Jujuy

Argentina

claudiogaviles@fhycs.unju.edu.ar

https://orcid.org/0000-0001-5631-0241

\section{Resumen}

En el marco de un contexto de transformaciones producto de los procesos de convergencia digital, el periodismo incorporó en sus rutinas y temarios a un fenómeno discursivo social que ha cobrado una notoriedad innegable: el meme.

Este artículo explora algunas relaciones entre memes y periodismo, desde la base de la teoría de los discursos sociales y desde una dimensión de la cultura contemporánea definida como snack. Se presentan los resultados de una investigación desarrollada desde una perspectiva metodológica interpretativa y sustentada en el análisis de contenido.

En su desarrollo, este trabajo analiza distintas tendencias y tipologías en las que los memes adquieren un valor noticiable y ocupan un lugar en el temario periodístico de diarios 
digitales. Se caracteriza la noticiabilidad de acontecimientos sociales que se producen a partir de la circulación viral de determinados memes; se presentan algunas variables en las que los memes y algunos escenarios en torno a ellos se integran en la agenda de fuentes de información y se usan como recursos para la interacción y la opinión. Se concluye con algunas consideraciones sobre la influencia del fenómeno de los memes en las propias prácticas periodísticas y en la relación con los usuarios digitales.

Palabras clave: periodismo; memes; noticias; cultura snack.

\section{Abstract}

In a context of transformations as a result of digital convergence processes, journalism put particular emphasis on incorporating into its routines and agendas a social discursive phenomenon that has gained undeniable notoriety: the meme.

This article explores some relationships between memes and journalism, from the basis of the theory of social discourses and from a dimension of contemporary culture defined as snack. The results of an investigation developed from an interpretive methodological perspective and supported by content analysis are presented.

In its development, this work analyzes different trends and typologies in which memes acquire the value of news and occupy a place in the journalistic agenda of digital newspapers. The newsworthiness of social events that occur from the viral circulation of certain memes is characterized. Some variables are presented in which memes, and some scenarios around them, are integrated into the agenda of information sources and as resources for interaction and opinion. And it concludes with some considerations on the influence of the phenomenon of memes in journalistic practices themselves and in the relationship with digital users.

Keywords: journalism; memes; news; snack culture.

\section{Introducción}

Hoy el periodismo es diferente a lo que era hace 10 años. Las noticias son diferentes, los procesos de producción y las instancias de reconocimiento tuvieron variaciones, los 
dispositivos tecnológicos se han transformado también y las formas de acceder y percibir la actualidad asimismo están cambiando.

Entre esas transformaciones, el periodismo puso atención especial e incorporó en sus temarios y en sus fuentes de información a un fenómeno discursivo social que ha cobrado una importancia y notoriedad innegable: el meme.

Esta pieza comunicacional visual aparece en las redes sociales mediáticas cuando hay un sentimiento, idea o crítica social que necesita expresarse. El meme resulta un discurso breve, anónimo e individual, que pone en común opiniones, críticas, ideas sobre la actualidad social; invita a ser compartido y abre las puertas a su transformación para una co-creación colectiva. Este fenómeno comunicacional despierta el interés en virtud de la relación entre una idea o construcción cultural breve y su capacidad de apropiación y réplica por una colectividad sin un acuerdo previo.

En ese marco, este trabajo explora las relaciones particulares entre memes y periodismo. Para ello se inscribe en el marco de la teoría de los discursos sociales, en tanto conjunto de hipótesis sobre los modos de funcionamiento de la semiosis social (Verón, 1996) y que procura el entendimiento de la dimensión significante de los fenómenos sociales, entendidos éstos como procesos de producción de sentido. Por lo tanto, el discurso mediatizado que aborda este trabajo, definido como discurso social, se entenderá desde una perspectiva sociológica y comunicacional, como el proceso a partir del cual se construye la realidad de lo social (Verón, 1996).

A su vez, resulta necesario enfatizar que la concepción de discurso social excede lo estrictamente lingüístico y se entiende desde la articulación entre los tres órdenes contemplados por la semiótica peirciana: lo icónico, lo indicial y lo simbólico. Consecuentemente, es entre estos tres órdenes en donde se configura la producción de sentido, por lo que se podría decir, siguiendo a Eliseo Verón (1996), que el surgimiento de la cultura y la conformación de las sociedades se define en gran parte por la trasferencia de esos órdenes sobre soportes materiales autónomos, en relación a un cuerpo significante; desde el arte rupestre hasta los medios de comunicación social tradicionales y las redes sociales mediáticas.

De esta manera, se considerará al discurso periodístico y a los textos breves que circulan en las redes sociales mediáticas como discursos sociales entre muchos otros; que 
desde su especificidad y centralidad actúan de manera significativa en la vida cotidiana, filtrando y configurando las realidades sociales, pero siempre en interrelación con la sociedad a la que pertenecen.

Por otra parte, problematizar las relaciones entre periodismo y memes amerita un acercamiento a una dimensión de la cultura contemporánea que Scolari (2020) define como snack. El concepto de cultura snack procura considerar un conjunto de procesos culturales, sociales y específicamente comunicacionales de producción y circulación de una infinidad de piezas textuales breves que circulan de manera viral por las redes sociales mediáticas. El meme forma parte de ese universo micro-discursivo. Algunas de las características transversales que definen a la cultura snack permitirán aquí tener una base conceptual para trabajar en las relaciones entre memes y periodismo.

La brevedad es el primer concepto clave de la cultura snack y se manifiesta en operaciones de esencialización, minimalización, supresión y toda acción de exacerbar las elipsis en las producciones textuales, al mismo tiempo que el lector deberá esforzarse para llenar esos huecos; aunque también podrá usar el texto, sobreinterpretarlo y expandirlo (Scolari, 2020).

Otro concepto clave es el de fugacidad. Con ella se hace referencia a la condición efímera de las piezas textuales breves que se disuelven en algunos segundos, que duran solo un rato hasta que llega el próximo texto, aunque esos textos queden disponibles en las distintas plataformas. El principio de fugacidad refiere al «consumo evanescente que propone la cultura snack, un proceso acelerado de evaporación de la semiosis y no tanto a la disponibilidad de ese contenido» (Scolari, 2020, p.162).

La fragmentación es el tercer concepto que nos permite pensar en la cultura digital contemporánea. Se puede considerar una triple fragmentación: en los textos, en los medios de comunicación y en las prácticas de consumo. Todas estas fragmentaciones estas interrelacionadas y no se pueden aislar, mientras que los formatos breves, como el meme, se adaptan, proliferan y se reproducen fácilmente y son consumidos en los intersticios de la cotidianeidad (Scolari, 2020).

Un concepto central que caracteriza a la cultura snack y a la esencia de los memes es el de viralidad. En el concepto confluyen las ideas de imitación, propagación y contagio. Cuando un meme entra en circulación por las redes sociales, compite con otros microtextos 
que también aspiran a la replicación; y surge un nuevo sentido de lo viral, como aquello que puede comentarse, evaluarse y compartirse en busca de la atención (Scolari, 2020).

En relación a lo antedicho, la remixabilidad resulta otro concepto propio de la cultura snack, que se basa en la fragmentación textual y define la posibilidad de la recomposición y creación de nuevas unidades textuales (Scolari, 2020) a partir de una pieza anterior. Las características actuales del entorno mediático propician la facilidad de producir, subir, bajar, reversionar, recircular e insertar contenidos (Jenkins, Ford y Green, 2015).

Finalmente, el concepto de aceleración resulta un principio fundamental de la cultura snack. Scolari (2020) recupera tres tipos de aceleración: tecnológica, la del cambio social y la del ritmo de vida. Y agrega la posibilidad de una cuarta, la aceleración de la producción, circulación y consumo textual, que se retroalimenta de las otras tres aceleraciones y cobra un impulso propio.

En relación a los memes, Scolari (2020) plantea que en la cultura snack todo texto breve adquiere la potencialidad de convertirse en meme, en tanto minibloques narrativos disponibles para su rápida circulación y reproducción en las redes sociales mediáticas.

En el marco de lo expuesto, este trabajo propone un análisis exploratorio en torno a las distintas tendencias y tipologías en las que los memes adquieren un valor noticiable y ocupan un lugar en el temario periodístico de los diarios digitales. Se propone también un análisis de la noticiabilidad de acontecimientos sociales que se producen a partir de la circulación viral de determinados memes; para concluir con algunas consideraciones sobre la influencia del fenómeno de los memes en las propias prácticas periodísticas y en la relación con los usuarios digitales.

En términos metodológicos se optó por una perspectiva epistemológica interpretativista, sustentada principalmente en la hermenéutica, adaptada al análisis de los medios de comunicación (Papalini, 2010; Ricœur, 1995; Thompson, 1993). Como técnica metodológica principal de recolección de datos, se consideró óptimo trabajar el Análisis de Contenido de Medios (Sánchez Aranda, 2005), debido a la pertinencia para procesar un gran volumen de información y la prestancia para trabajar respetando categorías y criterios unificados de análisis. El corpus de este trabajo estuvo constituido por noticias publicadas en las cuentas oficiales de Facebook, periodo 2018 a 2021, de los diarios digitales de referencia dominante en la provincia de Jujuy: El Tribuno de Jujuy, Somos Jujuy, Jujuy al Momento y Todo Jujuy. La 
estrategia de construcción del corpus implicó la selección de todas las noticias en las que se hizo referencia a "memes" en su construcción informativa.

\section{Teoría del meme (en Internet)}

La caracterización de los memes en la actualidad no resulta una tarea sencilla y mucho menos unívoca. El meme se presenta en las redes sociales mediáticas con distintos atributos y formatos: una fotografía, un dibujo o imagen, una combinación de fotografías y/o imágenes, una foto y/o imagen con texto, alguna frase escrita, la captura de pantalla de una escena fílmica con un texto, la captura de pantalla de una conversación de Whatsapp (eventualmente editada y modificada), de algún posteo o tweet, un gif, un sticker, un video en loop, entre otras posibilidades. Sin embargo, paradójicamente y a pesar de la eventual dificultad para poder categorizarlos, el meme resulta un género fácilmente reconocible por parte de los usuarios e incluso fácilmente remixable por muchos de esos usuarios.

Ahora bien, al momento de plantear un abordaje teórico en relación al meme, la mayoría de los trabajos académicos consultados recuperan como primeros antecedentes el campo conceptual denominado memética, desarrollado por Dawkins (1976). Desde dichas bases habría que identificar al meme como un agente activo que busca transmitirse, replicarse y difundirse para ser efectivo y lograr sobrevivir. Estas reflexiones teóricas son recuperadas por las ciencias sociales, y por la comunicación en particular, para poner en discusión los mecanismos de transmisión cultural y construcción social de significados y sentidos. En esa línea, los memes, en tanto unidades mínimas de información cultural, buscan propagarse viralmente, con las mismas mutaciones que podría sufrir un gen para poder buscar que su vida útil se prolongue. Cuanto más perdure en el tiempo y más sea copiado respetando la misma composición base, su éxito será mayor (Dawkins, 1976).

Así, se define como meme a aquello que es copiado (Dawkins, 1976), en torno a la noción de una unidad de sentido que se replica en distintos grupos dispersos geográficamente, ubicados en una temporalidad relativamente coincidente, pero con ciertos lazos de comunidad entre ellos (transmisión transversal) pero también hace referencia a una réplica longitudinal, en relación a una transmisión entre varias generaciones. Desde dicho en enfoque, la replicación se desarrolla en instancias en las que el meme es utilizado por múltiples personas 
reiteradamente, de manera que dicho uso se suma a un acervo que persiste en tiempo y espacio, y en su conjunto forman parte de una determinada cultura.

Como plantean pertinentemente Pérez Salazar, Aguilar Edwards y Guillermo Archilla (2014) la manera en que el meme se replica, pone en práctica procesos comunicativos en los que adquiere usos socialmente construidos, pero, a la vez, construyen diversos sentidos en torno a dicha reelaboración. Así, la representación de un meme adquiere un enorme potencial comunicativo, definido desde una dimensión sígnica, como discurso social, construye significados y en torno a ellos se articulan comunidades de sentidos compartidos.

Desde la pragmática resulta posible abordar al meme como un acto de habla, una unidad básica de la comunicación lingüística con la que se realiza una acción. Así el meme puede aludir a un referente más o menos concreto, y cuando es reconocido por los participantes en el acto comunicativo, efectivamente posibilita la puesta en común (Pérez Salazar, Aguilar Edwards y Guillermo Archilla, 2014), pero también la apropiación, la resignificación, la transformación, circulación y la viralidad.

Ahora bien, en el marco de este trabajo resulta necesario hacer referencia concretamente al meme en Internet. Así, y en base a lo antedicho, el meme será conceptualizado como una «unidad comunicativa digital que se constituye en un objeto digital compuesto, generalmente, a partir de una imagen reconocida socialmente (una imitación) sobre la cual se produce una intervención o manipulación que crea sentido o recrea el sentido original y es puesto en circulación nuevamente» (Venier, 2018, p. 29).

En este punto, resulta productivo recuperar una tipología propuesta por Danung y Attaway (2008) quienes plantean que en Internet se pueden identificar al menos dos clases de memes: 1) aquellos cuyos contenidos son copiados y transmitidos por los usuarios en los que no hay una modificación ni reinterpretación de la materialidad sígnica, y 2) aquellos memes en los que hay mayores posibilidades de llevar a cabo procesos de reinterpretación, con base en un formato que tiene un sentido general y que es adaptado por cada usuario, de acuerdo con una intención específica.

Venier (2018) profundiza lo planteado anteriormente y explica que una de las características principales de los memes es su capacidad de hacerse viral o expandirse por contagio en algún medio digital; y al ser usados regularmente se consolidan produciendo un «sentido de comunidad en un mundo fragmentado» (Shifman, 2014, citado por Grundlingh, 
2018, p. 154). Allí radica una motivación para que los usuarios participen en la circulación y reinterpretación de los memes en Internet, y se da a partir de la necesidad de pertenecer a una comunidad definida, al menos parcialmente, por estas prácticas culturales. En este sentido, Pérez Salazar, Aguilar Edwards y Guillermo Archilla (2014) resaltan de manera pertinente que los memes "hacen guiños" en relación con significados compartidos en el marco de ciertas comunidades de sentido, y como explica González Pérez (2019) un meme tendría un significado compartido únicamente por quienes lo han incorporado en sus repertorios culturales y quienes además pueden replicarlos luego con o $\sin$ modificaciones. A su vez, las modificaciones podrán iniciar un nuevo proceso de transformación de sentidos, ya que «una nueva forma de compartir un meme puede tomar nuevas significaciones en relación a las formas interpretativas y los repertorios culturales disponibles en nuevos grupos de intérpretes» (González Pérez, 2019, pp.63-64).

Finalmente, a los efectos de este trabajo, resulta productivo considerar dos conceptos que permiten dimensionar la comprensión actual del meme en Internet: el meme como artefacto y como género de la cultura digital participativa (Wiggins y Bowers. 2015).

En primer lugar, considerar al meme como artefacto implica reconocer su fisicalidad virtual, desde el punto de vista cognitivo (existente en la mente humana) y digital (existente en las distintas plataformas mediáticas); reconocer que ofrece información sobre la cultura que lo crea y lo usa, sobre el comportamiento social de aquellos individuos o grupos que lo producen; y por último reconocer que los memes poseen una producción y un consumo intencionales entre los miembros de una cultura digital participativa (Wiggins y Bowers. 2015).

Por otra parte, considerar al meme como un género específico, implica identificar aspectos que permiten reconocer lógicas de producción y uso, que a su vez configuran competencias y usos posibles tanto en su diseño como en su lectura. Esto posibilita reconocer formas y estilos relativamente identificables y a la vez discernibles. Entender a los memes como género implica considerarlos como un sistema complejo de motivaciones sociales y de la actividad cultural que es resultado de la comunicación, y son centrales para entender la cultura (Wiggins y Bowers. 2015).

\section{Redes sociales mediáticas y periodismo}


La incorporación y uso paulatino de las redes sociales digitales en los medios de comunicación tradicionales a partir del año 2009, produjo un proceso de transformaciones y adaptaciones de las rutinas productivas y narrativas del periodismo.

Las redes sociales fueron configurando un nuevo ecosistema periodístico en el que todas las actividades realizadas por sus actores fueron cambiando la experiencia tradicional, y reconvirtiendo a la noticia en un proceso dinámico y colectivo antes que en un producto cerrado (Noguera Vivo, 2013). En este sentido, el flujo de las redes sociales fue alterando y desordenando las secuencias productivas que tenían los medios tradicionales: recopilar y seleccionar información, producir noticias, editarlas y jerarquizarlas y luego distribuirlas y comercializarlas. Esa secuencia se ve hoy alterada disruptivamente por las redes, ya que los medios y los periodistas comienzan a perder la exclusividad en la construcción de información y en la imposición de agendas (Cerezo, 2016), porque se reconvierten los modos de recolectar datos, de comunicar, compartir y de mostrar las noticias en los distintos medios y plataformas.

Asimismo, este complejo entorno mediático fue configurando audiencias múltiples, ya que prácticamente ningún conjunto de sujetos sociales es audiencia de un solo medio. A su vez se configuran audiencias-usuarias de múltiples dispositivos y plataformas en la web que les posibilita distintas instancias de intervención: como lectores, oyentes y televidentes, pero también como fuentes, productores y distribuidores de información.

La construcción de la opinión pública, así como busca la información periodística sobre la cosa pública, también se informa a través de otro tipo de datos (farándula, modelos de vida, parodias, memes, etc.) y en dicho consumo es posible que los usuarios no reconozcan como necesaria la información sobre la realidad política, económica, social y/o que se vea degradado el sentido de aquellas noticias que dan marco de lo que pasa (Martini, 2017).

En ese complejo contexto, el periodismo se ve en la necesidad de captar la atención o no perder vínculo con sus audiencias que ahora tienen prácticas de consumo informativo multiplataforma. Esta situación impulsó casi obligatoriamente a los medios y al periodismo a incorporar las redes sociales digitales y sus contenidos en sus rutinas productivas, utilizándolas con diversas estrategias y finalidades.

El uso expansivo que el periodismo hace de las prestaciones de Internet en general y de las redes sociales en particular da cuenta claramente de un fenómeno disruptivo que, en diversas maneras, moviliza y pone en crisis las tradicionales formas de pensar y hacer 
periodismo. Se produjeron numerosos cambios productivos y adecuaciones en las construcciones discursivas y narrativas, se fueron aprovechando diversificada y creativamente las potencialidades que ofrece internet y las redes sociales para proponer nuevas formas de distribución y recopilación informativa, como también para ensayar nuevas alternativas de relación con las audiencias ahora devenidas en usuarios.

En este sentido, la insistente disputa de los medios informativos por marcar presencia en el entorno de las redes sociales, principalmente en Facebook, Twitter e Instagram, reside en la imperiosa necesidad de defender la posición de autoridad como proveedores privilegiados de información periodística. Esa defensa implica competir en el entorno de las redes sociales, intermediarias informativas, ya que resulta en apogeo el desplazamiento y uso que los usuarios hacen de estas para acceder a la información de actualidad.

En este contexto se enmarca el interés de este trabajo por poner el foco en la relación entre memes y periodismo como actor social que defiende su posición en la construcción del presente social de referencia, que aporta bases referenciales fundamentales para la construcción de sentidos compartidos, pero que debe apelar a la construcción de nuevos contenidos informativos que den cuenta de nuevos procesos sociales y culturales.

\section{El meme como acontecimiento noticiable}

En el marco de los discursos mediáticos, el periodístico ocupa un lugar central en la vida cotidiana de las personas. De manera general, se podría definir a la tarea periodística como el trabajo de producción noticiosa que construye una parte de la realidad social y que posibilita a las personas el conocimiento de una parte de la realidad a la que no pueden acceder de manera directa (Martini, 2000). La novedad y la actualidad son los principales factores que convierten a un hecho en digno de ser noticia, hasta el punto de que la actividad periodística se reconoce porque selecciona y difunde los llamados hechos de actualidad (Fontcuberta, 1993). Sin embargo, los datos nuevos y actuales pasarán a ser periodísticos sólo cuando se les haya atribuido un significado y una contextualización en torno a un conjunto de supuestos, creencias y valores, adquiriendo así un carácter ideológico (Fontcuberta y Borrat, 2006).

Considerada como cualidades o valores que deben tener los acontecimientos para ser noticia, la noticiabilidad resulta un terreno y contexto para la imposición de un sentido de 
actualidad. Como una categoría situada históricamente, el valor de noticiabilidad responde a la realidad de la época, sus características y a lo que en cada momento una sociedad considera de interés, ya que el acontecimiento es también cultural (Martini, 2017).

Los valores de noticiabilidad más comunes en los medios podrían sintetizarse en la novedad, la originalidad e imprevisibilidad, la gravedad, la calidad y cantidad de personas implicadas, la proximidad, el interés, los efectos posibles sobre la sociedad, la conflictividad, la rareza, entre otros. Y en la actualidad, según propone Martini (2017), el valor de novedad se ve alterado por la velocidad y aceleración de los acontecimientos, la espectacularidad; que a su vez se hace escándalo.

En ese contexto, en el periodismo digital actual, los memes adquieren el valor de acontecimiento noticiable cuando cumplen con, al menos, dos características reconocibles en su circulación en las redes sociales mediáticas: 1) la irrupción masiva y acelerada de memes en torno a un hecho de actualidad mediática y 2) la viralización de un meme (o grupo pequeño de ellos) acerca de un acontecimiento con valores noticiables.

\section{Estallaron los memes}

La mayor cantidad de noticias que abordan a los memes como acontecimiento, en el corpus estudiado, resultan aquellas que dan cuenta de un proceso de irrupción masiva y acelerada de memes en las redes sociales mediáticas. De manera generalizada, dichas irrupciones se producen a partir de la circulación de memes cuyos contenidos se vinculan con acontecimientos mediáticos y/o noticias previamente publicadas, que despiertan el interés social y la necesidad de expresión y opinión en virtud de valores como la gravedad, la rareza, la conmoción o la polémica en torno a temas políticos, económicos, artísticos o deportivos.

Sin embargo, en los casos referenciados, el acontecimiento noticiable resulta el propio proceso de irrupción de memes en las redes sociales, siempre que dicha irrupción resulte relativamente masiva y acelerada.

Las modalidades denominativas que propone el periodismo para la representación de estas irrupciones de memes apelan a nociones asociadas a la explosión, a la aparición de ondas repentinas de gran amplitud, al atiborrado del espacio mediático, a nociones asociadas a la revolución, guerra, estampida, entre otras alternativas. En los títulos de las noticias se 
reiteran expresiones como: "estallaron los memes", "ola de memes", "catarata de memes", "explotaron los memes", entre otras.

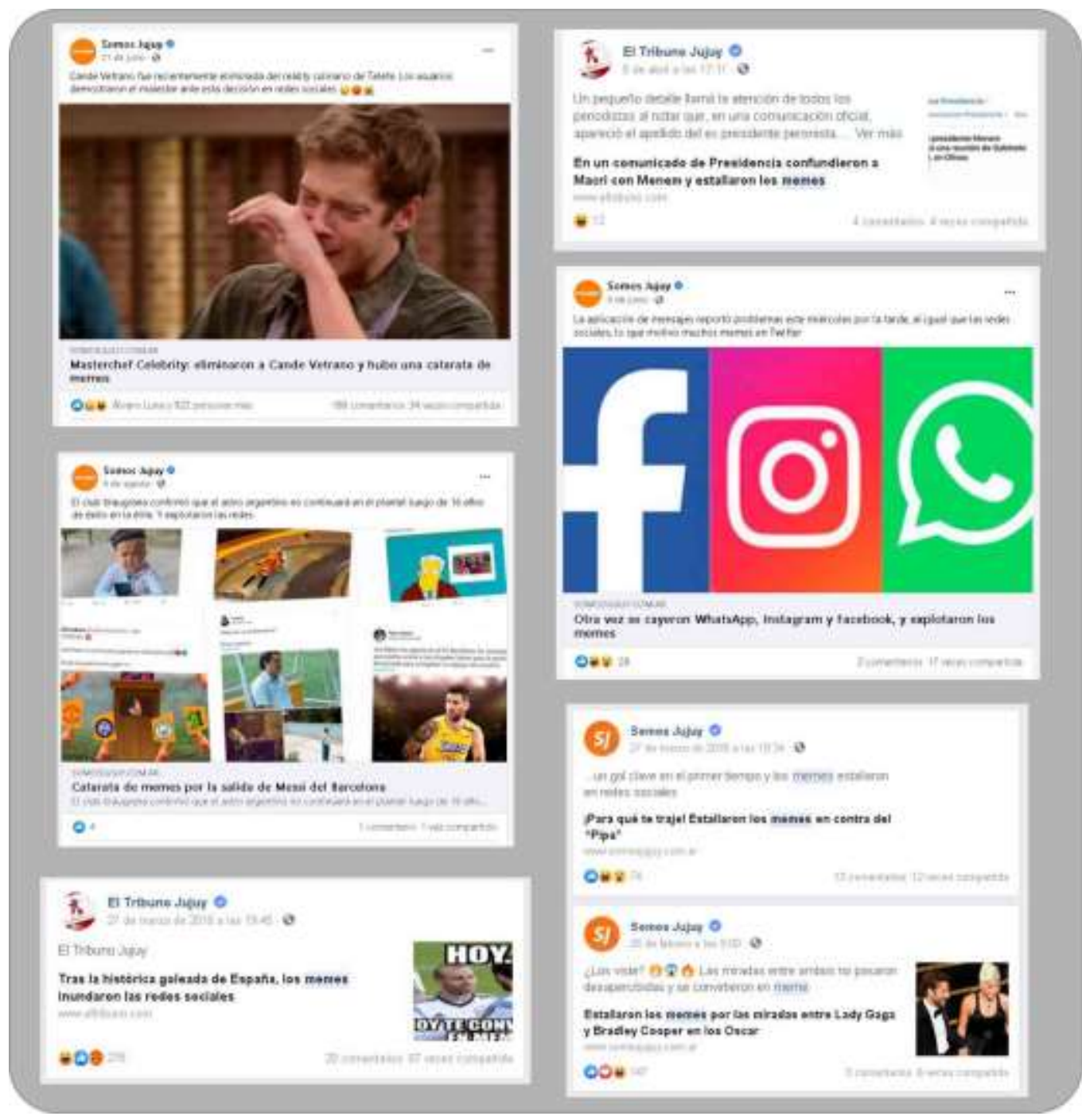

Figura 1. Capturas de pantalla de redes sociales referenciales a la categoría "estallaron los memes" (Fuente: elaboración propia)

Las notas periodísticas sobre estallidos de memes presentan una tendencia relativamente homogénea en cuanto a su estructura referencial y redaccional: se describe el 
hecho mediático que da origen a las opiniones, críticas y/o puntos de vista que proponen los memes y seguidamente se presentan una selección de entre cinco y quince memes vinculados al tema.

Podría interpretarse que los memes en su estado de irrupción masiva y espontánea permiten al periodismo canalizar ciertos flujos de opinión y resultan útiles para monitorizar ciertas tendencias de referencialidad sobre un tema, en determinado momento y lugar. En este sentido se podrían identificar ciertas similitudes con el manejo periodístico de los hashtags y trending topics de Twitter, con la diferencia de que la construcción periodística del "estallido de memes" nunca se presenta respaldada por un criterio de cuantificación de piezas de memes relevados o datos sobre tráfico de circulación de dichas piezas.

Por otra parte, una variante en la construcción periodística de noticias sobre irrupción de memes resulta aquella en la que la nota ofrece explícitamente una selección o ranking de memes sobre el hecho de actualidad. 


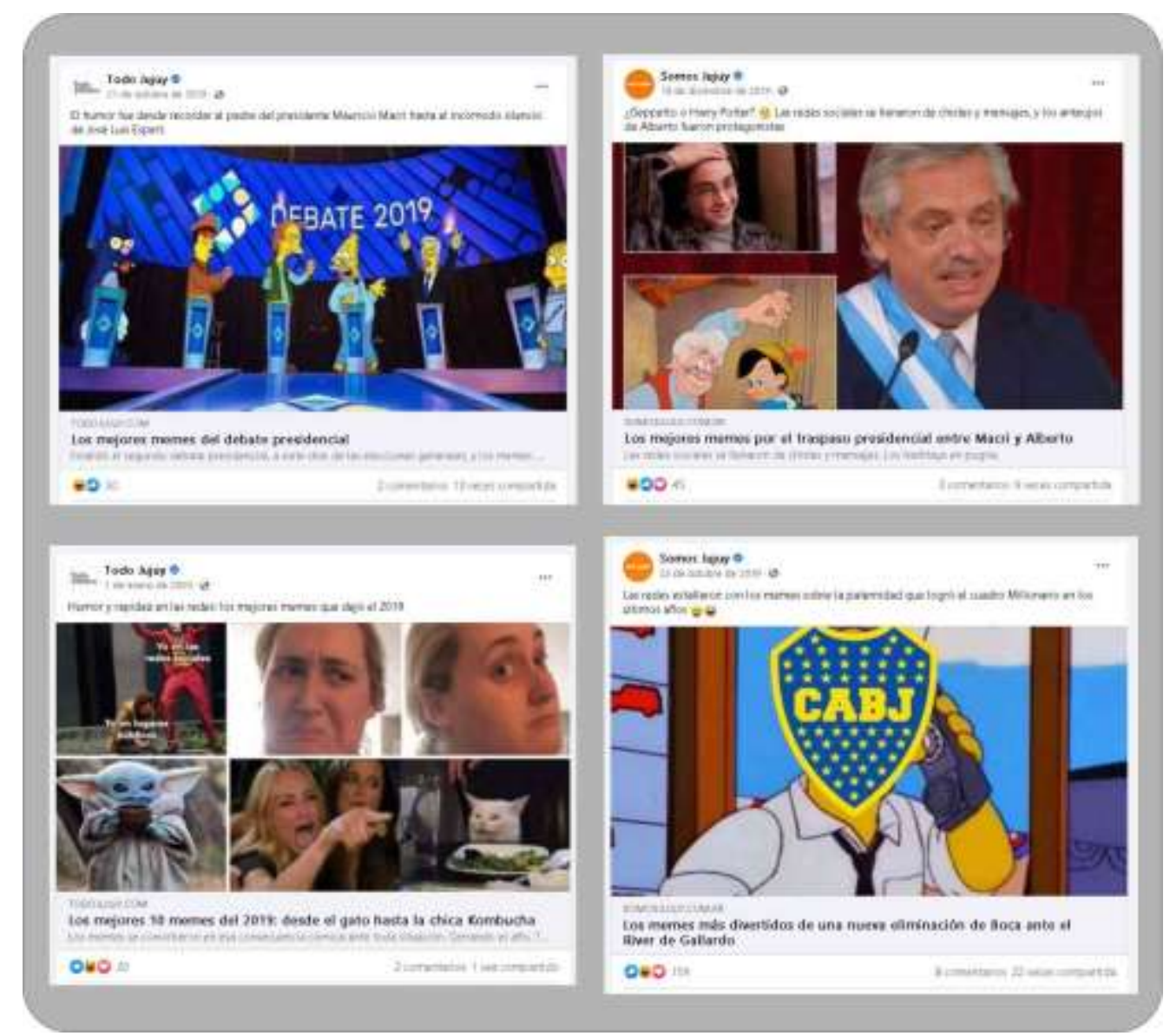

Figura 2. Capturas de pantalla de redes sociales referenciales a la categoría "selección de memes" (Fuente: elaboración propia)

En estos casos, la noticia sobre memes opera como una propuesta aglutinadora que intenta mitigar la fragmentariedad que caracteriza la circulación y consumo de los memes en las redes sociales. El periodismo se apoya en el mayor o menor conocimiento de los hábitos de lectura / consumo de su audiencia, en el marco de la circulación informativa de la cultura snack, $y$ les ofrece un acceso seleccionado para el consumo de memes de manera organizada y concentrada en una sola nota; consumo que la audiencia, de otra manera, tendría que visualizar de manera desorganizada, descentralizada y fragmentada en el entorno de las redes. 


\section{Se hizo viral}

Como se dijo precedentemente, una segunda alternativa en la que los memes adquieren el valor de acontecimiento noticiable se produce cuando un meme en particular o un grupo reducido de ellos se hace viral en las redes sociales.

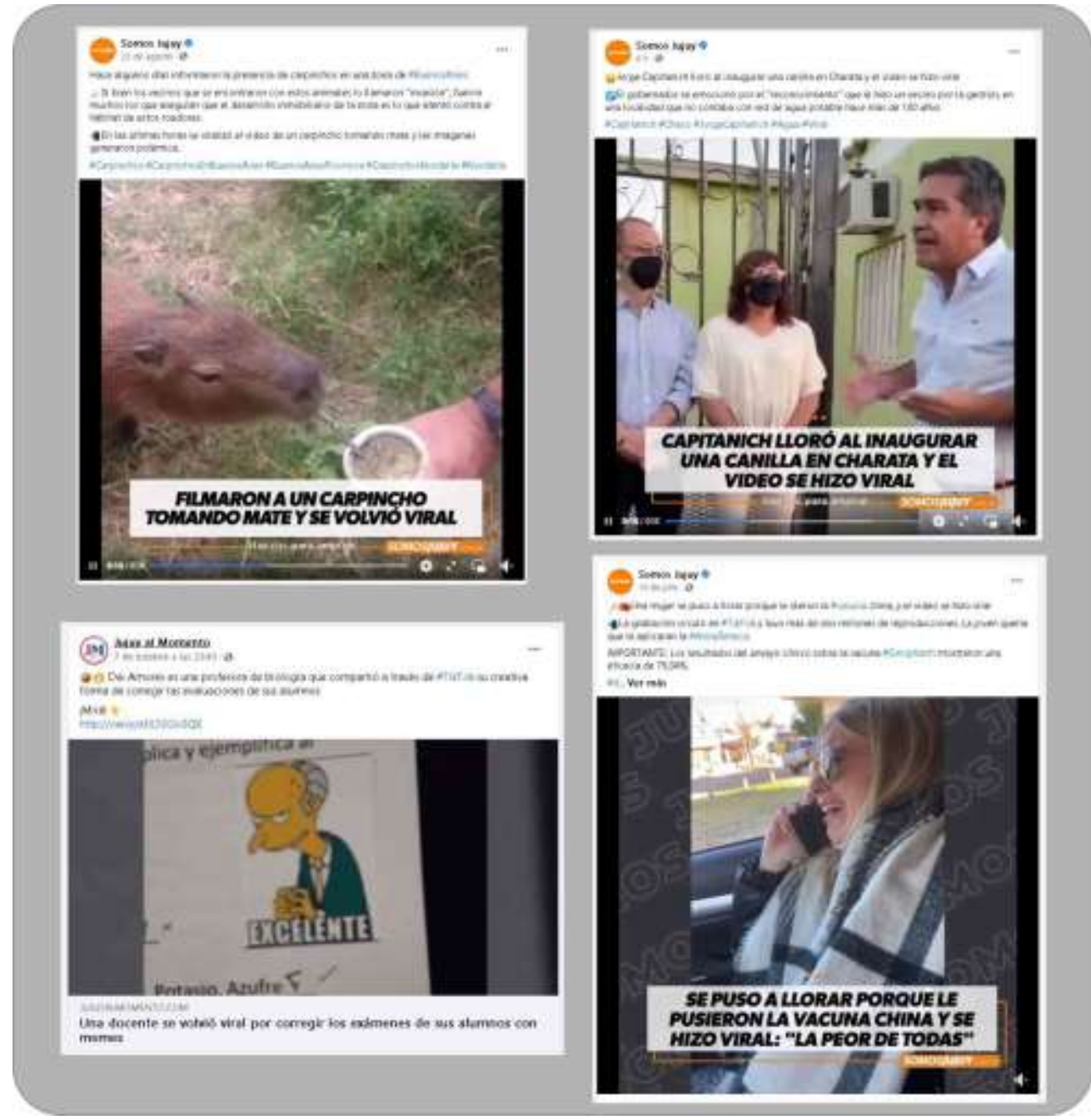

Figura 3. Capturas de pantalla de redes sociales referenciales a la categoría "se hizo viral" (Fuente: elaboración propia)

La principal diferencia con el proceso de "estallido de memes" es que en este caso no se produce una irrupción de múltiples memes, con distintas perspectivas sobre un tema 0 
hecho de actualidad, sino que el hecho noticiable se reconoce periodísticamente en el proceso de reproducción acelerada y por contagio del meme en las redes digitales; es decir cuando un meme concreto adquiere el estatus de viral. Otra diferencia se evidencia en que los memes virales no necesariamente resultan hechos de actualidad cubiertos previamente por el periodismo, ya que muchos memes virales tienen como protagonistas a los propios usuarios 0 son estos los que capturan la imagen o filman el video que luego se hace circular en las redes y capta la atención periodística.

La tendencia periodística para convertir en noticia memes virales se respalda en que los contenidos de dichos memes (estáticos o dinámicos) responden a diversos criterios habituales de noticiabilidad como, por ejemplo, la novedad, el carácter disruptivo del hecho fotografiado o filmado, la rareza, lo insólito, lo imprevisto, el conflicto o el protagonismo de figuras públicas o famosas, entre otras posibilidades.

Entonces, la circulación viral del meme es lo noticiable. Sin embargo, podría plantearse también que lo viral refuerza la noticiabilidad porque se legitiman valores otrora igualmente noticiables en las acciones de réplica masiva que realizan los usuarios.

Finalmente, como se planteó en el caso de los estallidos de memes, las noticias sobre viralización de memes tampoco se respaldan en datos precisos de cantidad de reproducciones u otra información de circulación, sino que resulta una construcción intersubjetiva de la producción periodística.

\section{Otras tendencias y tipologías de presencia y uso de los memes en el periodismo}

Más arriba se conceptualizó al meme como una unidad comunicacional de la cultura actual, que construye significados y en torno a los cuales se articulan comunidades en torno a sentidos compartidos. De esa manera, entendido como discurso social y en su dimensión de signo, los memes contribuyen a la configuración de significados compartidos entre las cuales el periodismo opera de manera influyente, pero también es influenciado.

Desde dicha perspectiva, resulta posible plantear que el periodismo encuadra su construcción informativa haciendo foco en algunas otras instancias sociales en las que interpreta a los memes como un género que recupera y reinterpreta parte del complejo sistema de motivaciones sociales y culturales contemporáneo. Así, el periodismo no solo considera a un meme viral o a la irrupción masiva de memes como hechos noticiables, sino que además se 
ocupa de considerar otras vinculaciones y reacciones que los memes provocan en el contexto social, pero además el periodismo también usa los memes como herramientas de interacción y opinión en sus propias prácticas cotidianas.

En base a la investigación realizada, se desarrolla brevemente a continuación estas otras tendencias y tipologías de relación entre memes y periodismo.

\section{Cuando la noticia es la trastienda del meme}

La construcción de comunidades de sentido en torno a los memes configura socialmente un grado de interés compartido en torno a ciertos contenidos que circulan por las redes. Si bien muchos memes construyen significados y sentidos a partir de la manipulación y resignificación de imágenes y fotografías de ciertos personajes públicos y/o mediáticos, se crean también muchos memes en los que los protagonistas resultan personas anónimas. Esas personas protagonistas de ciertos memes cobran notoriedad y adquieren fama relativa a partir de los procesos de viralización.

Ahora bien, en el análisis de las noticias relevadas para este trabajo, se pudo advertir que el periodismo tiende a atribuir valores de noticiabilidad a las informaciones de la trastienda de los personajes de ciertos memes. 


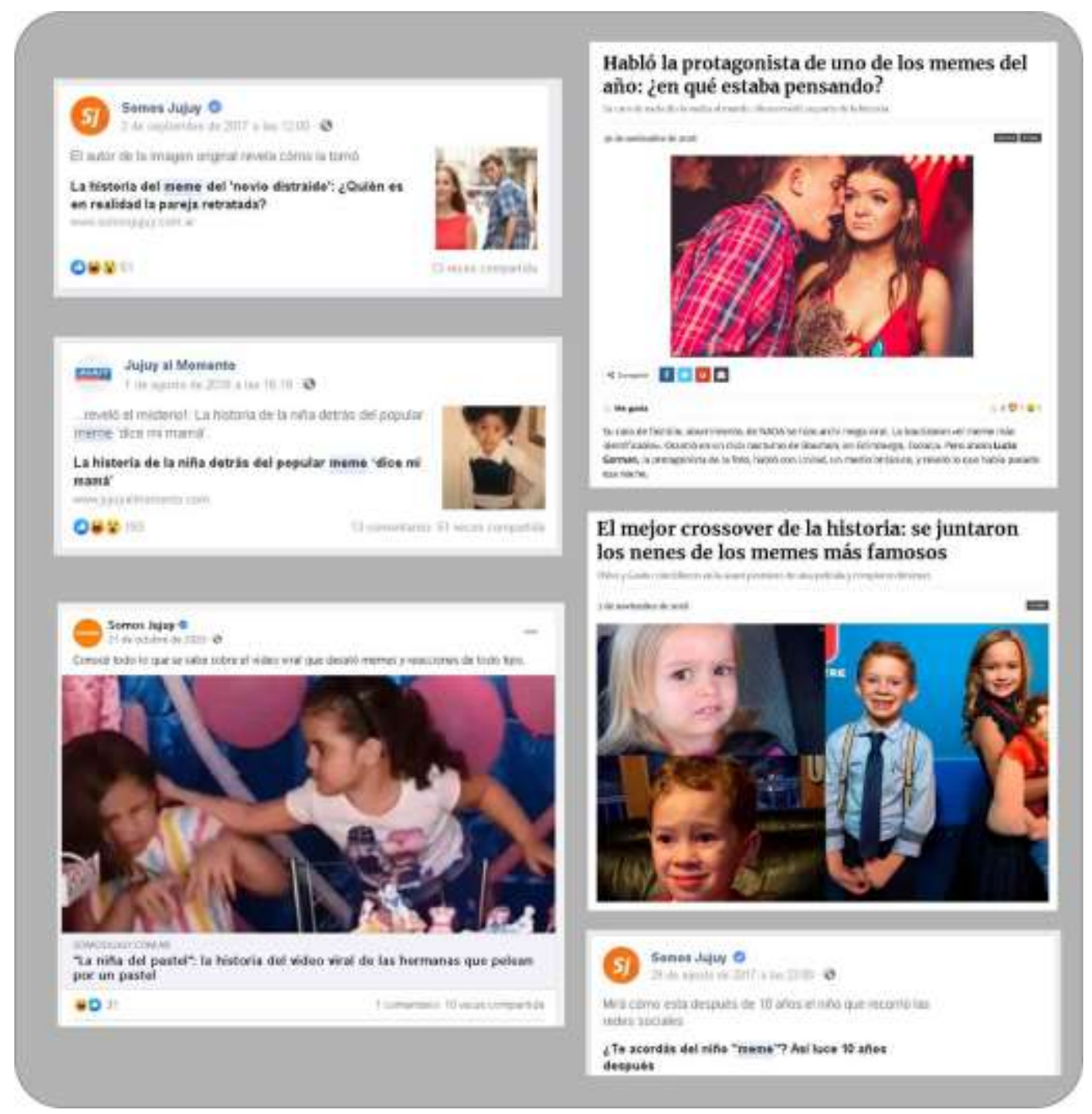

Figura 4. Capturas de pantalla de redes sociales referenciales a la categoría "la trastienda del meme" (Fuente: elaboración propia)

En ese sentido, develar el anonimato de los nombres y facetas de las historias de vida de los personajes de los memes resultan hechos noticiables. Reconstruir o conocer las incidencias empíricas de lo que ocurría en el momento de la toma fotográfica que sirvió de base para la producción de un meme resulta otro valor de noticiabilidad. Conocer el presente 
y/o facetas de la vida cotidiana de personajes de memes con cierta historia transcurrida resulta otro criterio de noticiabilidad posible; entre algunos otros.

En síntesis, se podría analizar que, en estos casos considerados, el periodismo busca conocer y hacer noticia el componente "empírico", "material", "real" de aquellos protagonistas de los memes que adquieren una vida propia (o varias) en el entorno virtual. El valor de noticiabilidad se asocia fundamentalmente con la intención de poner en común con los usuarios historias de la persona detrás del personaje memético: de sus identidades, de sus historias de vida, sus gustos, sus cambios físicos, cómo los afectó en su vida cotidiana haber sido protagonista de memes virales, entre otras alternativas.

\section{Cuando la noticia es la reacción pública a los memes}

Como se mencionó más arriba, un conjunto amplio de memes se produce sobre la base de la información sobre ciertos acontecimientos de la realidad que se conocen socialmente a partir del rol de intermediación que cumple el periodismo. Cuando ciertos acontecimientos despiertan interés colectivo, influyen, afectan, perjudican y/o modifican ciertos procesos o prácticas sociales aparece el meme como discurso que reacciona y pone en común ciertas opiniones, críticas, burlas o demandas en torno a los acontecimientos públicos. En dichos procesos comunicacionales el meme, desde su carácter anónimo, suele referenciar explícitamente (desde lo textual o lo visual) a las personas protagonistas de los acontecimientos y canalizar los juicios de valor de manera más o menos directa, apelando a diferentes estrategias que pueden oscilar entre lo cómico y burlesco hasta lo ofensivo y/o discriminatorio.

Ahora bien, en ciertas ocasiones, en la continuidad del proceso de circulación informativa, el meme o el conjunto de memes que expresa opiniones sociales provoca la reacción y manifestación pública de las personas implicadas en los acontecimientos que provocaron la irrupción de los memes. En estos casos, esa reacción o respuesta ante los memes se convierte en un nuevo acontecimiento noticiable, en el que el periodismo hace foco. 


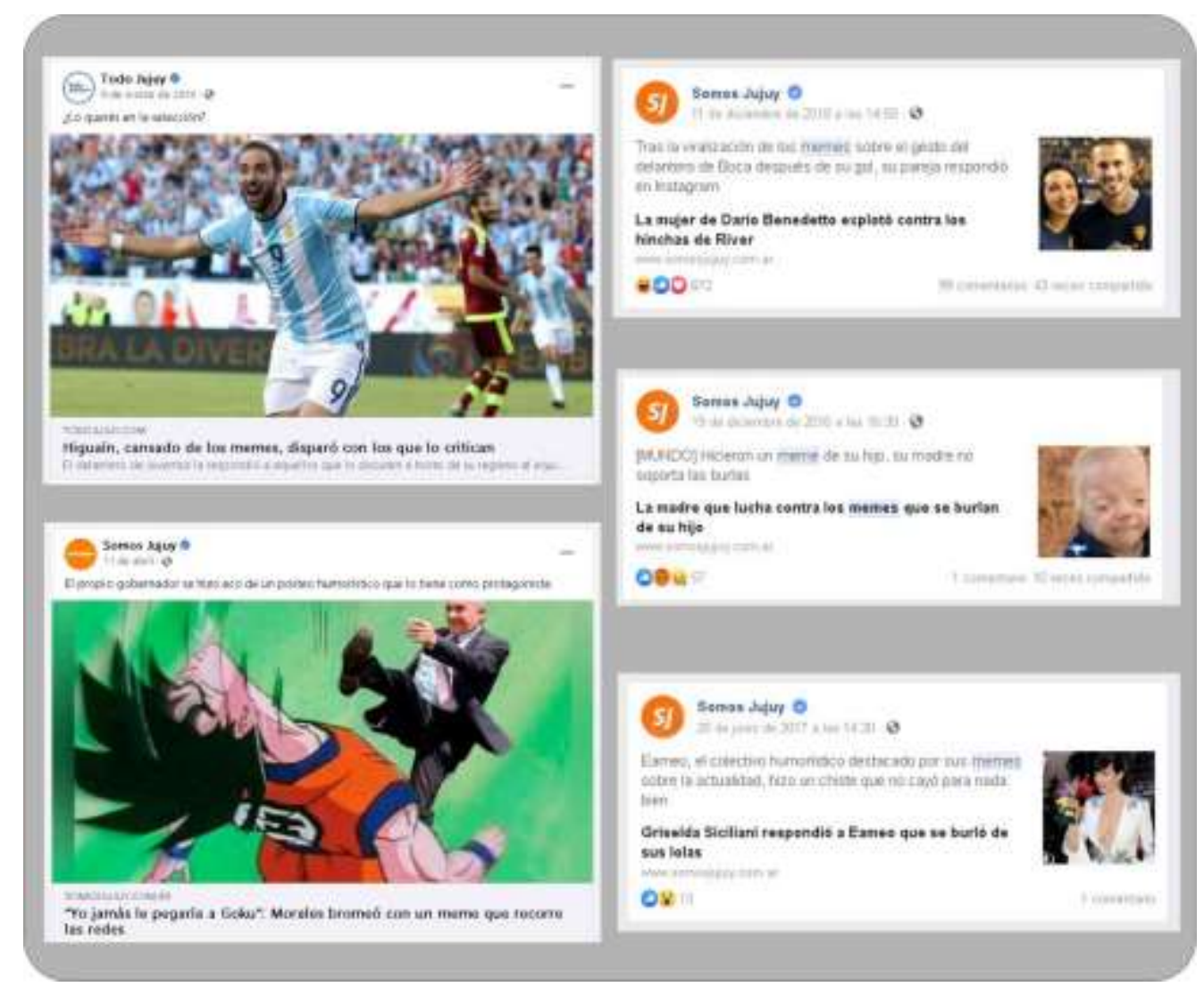

Figura 5. Capturas de pantalla de redes sociales referenciales a la categoría "reacción a los memes" (Fuente: elaboración propia)

En estos casos el valor noticia está puesto en el conflicto, en el enfrentamiento, en la oposición entre una persona que cobró estado público inicialmente a partir de la noticia, que fue blanco de la opinión social a través de los memes y que luego responde a un colectivo anónimo y difuso.

\section{Cuando el periodismo demanda memes}

Entre las diversas transformaciones que se propiciaron en el periodismo con la convergencia digital, las posibilidades de interacción con audiencias y lectores resultan unas de las más desafiantes y disruptivas. El uso de las redes sociales mediáticas en las prácticas periodísticas aporta una potencial herramienta de interacción y expansión de dinamismo entre medios y audiencia, pudiendo aportar fluidez, rapidez e instantaneidad a la relación. 
En la actualidad, uno de los usos de las redes sociales responde a la promoción de instancias de interacción, en la que conductores y/o periodistas promueven la participación de la audiencia a partir de distintas estrategias de consulta de opinión o de aporte de contenidos mediante el uso de Facebook, Twitter o Instragram; los que luego son incorporados eventualmente a los contenidos periodísticos.

En el caso que ocupa a este trabajo, se pudo advertir que el meme se incorpora periodísticamente como un recurso para promover la interacción con las audiencias.

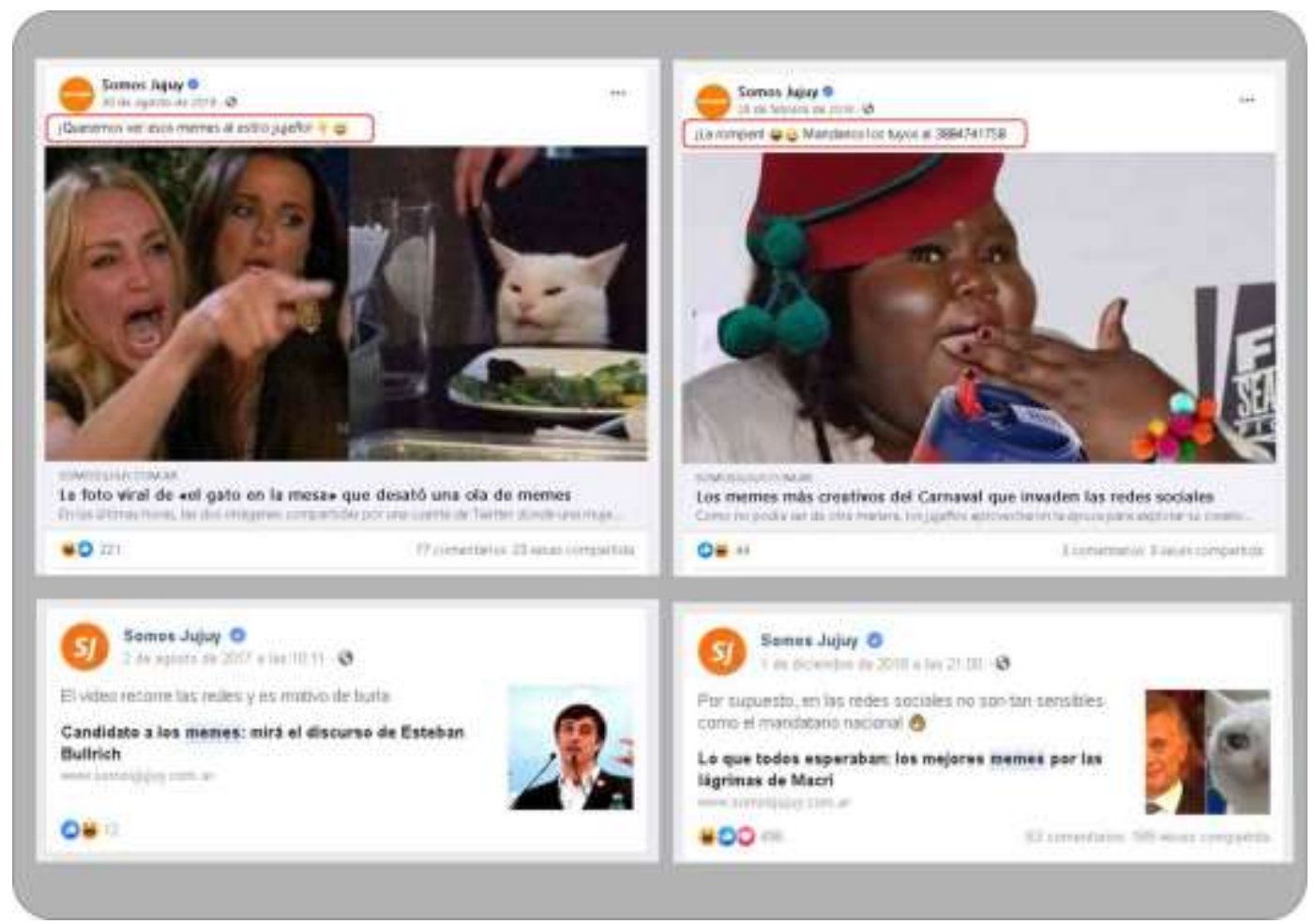

Figura 6. Capturas de pantalla de redes sociales referenciales a la categoría "el periodismo demanda memes" (Fuente: elaboración propia)

Al ser el meme una práctica de comunicación que surge en la sociedad, y por ende en las audiencias, desde el periodismo se insta a los usuarios a la producción y/o envío de memes ante la propuesta de ciertos temas. Estas demandas se advirtieron en, al menos, dos modalidades. Una de ellas fue el pedido explícito de envío de memes a través de los espacios para comentarios y sistemas de mensajerías de las redes sociales, como Facebook y 
WhatsApp; estrategia que representa una propuesta de interacción directa. Una segunda alternativa se interpreta como una invitación abierta o indirecta, en la que el medio sugiere que ciertos acontecimientos públicos ameritan o merecen la irrupción de memes.

\section{El meme como recurso de editorialización indirecta}

Como se explicó más arriba, el discurso periodístico se estructura principalmente en torno a un eje informativo, anclado en la noticia. Sin embargo, un segundo eje en el que se cimenta la actividad periodística resulta el discurso argumentativo y de opinión sobre la actualidad.

El discurso periodístico argumentativo se caracteriza por la búsqueda de la persuasión, apelando a la capacidad de razonamiento de la audiencia para convencerla sobre determinados enfoques (Martini, 2000). Esa búsqueda de convencimiento implica una exposición selectiva de determinados aspectos sobre los acontecimientos con el objetivo de brindar elementos de juicio para que la audiencia elabore su propia reflexión sobre determinado asunto (Clauso, 2007). El discurso argumentativo se nutre libremente de elementos de análisis, interpretación y opinión, mientras que, a su vez, permite expresar la postura ideológica o mirada analítica respecto de los acontecimientos sociales de los que da cuenta. Dicho posicionamiento puede ser asumido de manera individual, por un periodista, analista o comentarista, o bien de manera institucional, en la que es un medio de comunicación, espacio periodístico o programa quien asume una postura editorial respecto de los acontecimientos. En términos de formatos, se pueden mencionar un grupo de textos ampliamente reconocidos como la nota de opinión o el comentario, el editorial, la crónica, la crítica, la entrevista de opinión, entre otros.

Sin embargo, en el escenario de textos periodísticos de opinión, podría identificarse una variedad que resulta frecuente, aunque menos expandida y que consiste en el abordaje argumentativo, crítico o valorativo de aspectos de la realidad, pero apelando al recurso del humor y la ironía. Este recurso puede identificarse, pero no se le puede asignar una descripción formal concreta ya que resulta una estrategia libre y creativa. Por otra parte, la responsabilidad autoral de estos textos puede estar explícita, puede ser asumida por el medio o empresa periodística o puede ser difusa y despersonalizada, como es el caso de los personajes ficticios. 
En el marco de la utilización del humor e ironía como formato de opinión o argumentación, resulta posible identificar el uso y apropiación de los memes como estrategia periodística para editorializar sobre acontecimientos o hechos de la realidad social actual.

En ese sentido, caracterizar a los memes como recurso de editorialización periodística implica pensarlos como una estrategia general más que como un formato particular.

En los casos estudiados para este trabajo, se pudo identificar esta estrategia en un medio en particular, el diario digital Jujuy al Momento, a partir de la selección y uso posterior de ciertos memes para la construcción de notas con un encuadre crítico hacia el Gobierno provincial. 


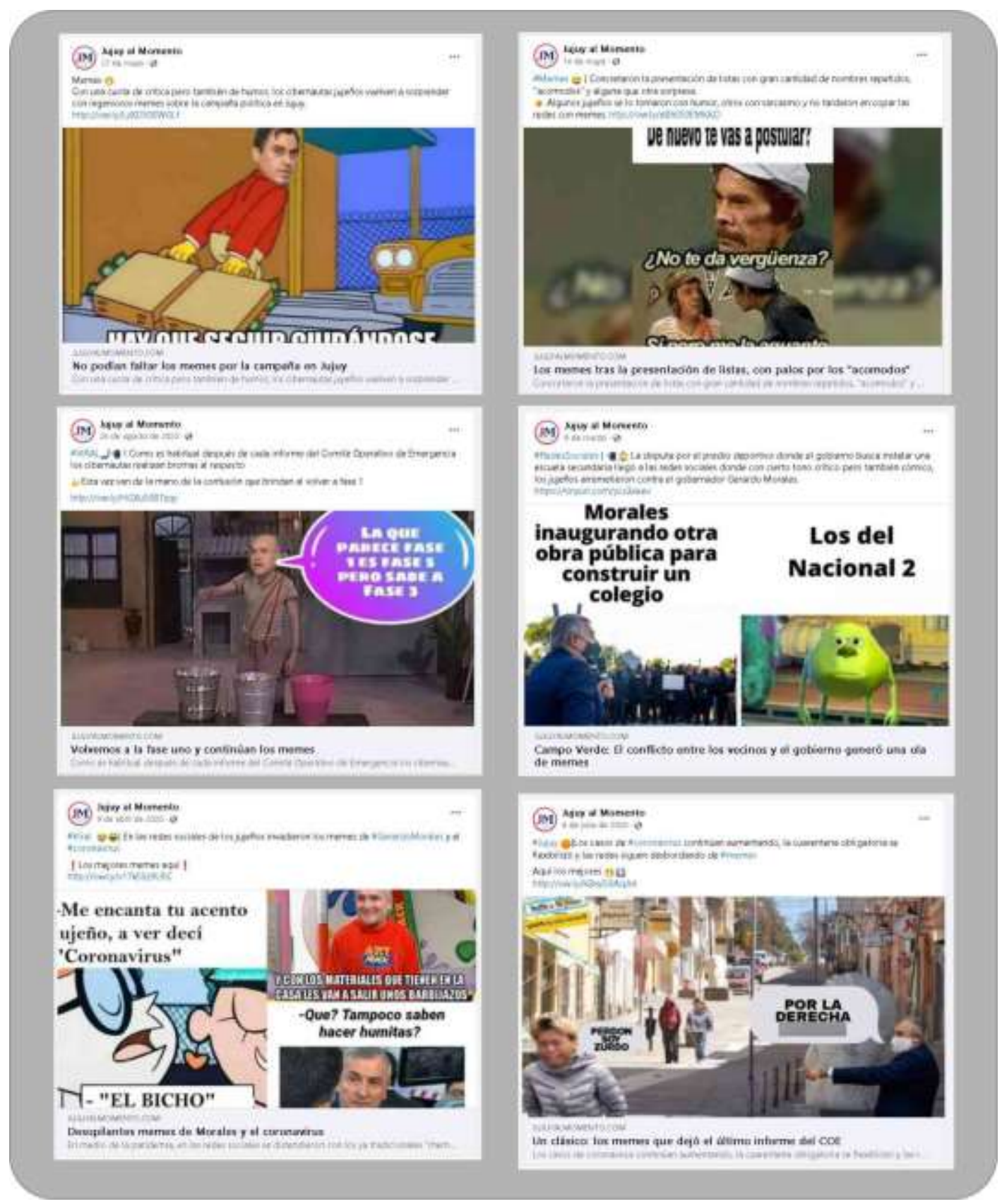

Figura 7. Capturas de pantalla de redes sociales referenciales a la categoría "el meme como recurso de editorialización" (Fuente: elaboración propia) 
La estrategia de editorialización se advierte no solo en la construcción de sentido que se propone desde la titulación y la redacción de cada nota periodística sino también, y fundamentalmente, en la recurrencia de notas que repiten el mismo encuadre argumentativo y crítico. A su vez, se propone la noción de editorialización indirecta ya que el medio no asume una postura crítica explícita, sino que actúa como intérprete e intermediario de la opinión pública, representada a través de los memes cuidadosamente seleccionados para responder al encuadre buscado. El medio opina a través del público y pone en práctica una estrategia similar a la de las consultas en la calle, pero esta vez a partir de la recopilación organizada de las expresiones espontáneas y despersonalizadas que se canalizan a través de los memes.

\section{Consideraciones finales}

Entre los memes y el periodismo se da una relación de mutua conveniencia. Por un lado, una amplia cantidad de memes necesitan del periodismo ya que su producción depende y se nutre necesariamente de los acontecimientos que toman estado público a partir del discurso periodístico o mediático. Por otro lado, como se propuso en este trabajo, el periodismo considera a los memes como acontecimientos noticiables cuando éstos cumplen con ciertas cualidades. Los memes, y el mundo en torno a ellos, pasan a integrar la agenda de fuentes de información para la producción de noticias y pasan a considerarse prácticas culturales a las que el periodismo debe considerar en sus prácticas de construcción informativa. A su vez, los memes son utilizados y apropiados por el periodismo para otros fines periodísticos como las instancias de promoción de la interacción o las estrategias de editorialización.

Ahora bien, además de lo anterior, se pueden abrir otras instancias de análisis para abordar y profundizar la relación entre memes y periodismo.

Aunque quizás de manera incipiente, los memes forman parte de un conjunto de discursos digitales que le disputan al periodismo la hegemonía de la producción y la distribución de información de actualidad.

Luego de que los memes se producen sobre la base de la información periodística, al viralizarse por las redes sociales mediáticas se convierten en nuevos puntos de acceso a información de actualidad para los usuarios. Este proceso puede propiciar en los usuarios nuevos hábitos y modalidades de consumo informativo snack: breve, reducido, acelerado, intersticial, fugaz y fragmentado, a su vez descontextualizado y con nulo o escaso desarrollo. 


\section{- CHE, ¿VISTE QUE DENUNCIARON}

A CRISTIANO RONALDO POR

ABUSO?

- SI, BAH, VI UN MEME SOBRE ESO.

- SI, YO TAMBIEN, HOY POR HOY

LOS MEMES SON LA UNICA FORMA

DE ENTERARME LO QUE PASA EN

LA ACTUALIDAD.

DOS PIBES DE UNOS 20 ANOS. COLECTIVO

152. ALTURA ALTO PALERMO, CABA.

VIERNES

Figura 8. Captura de pantalla de redes sociales (Fuente: elaboración propia)

Pero también, el consumo informativo a través de memes puede resultar el movilizador de atención e interés que impulse a los usuarios a buscar y acceder a otras fuentes informativas periodísticas tradicionales para ampliar y contextualizar la información.

En relación con lo anterior, los memes le disputan al periodismo la hegemonía en la interpretación y opinión sobre los hechos de actualidad. La crítica desde el humor y la ironía que proponen extendidamente los memes, resulta un discurso argumentativo y de opinión que incluso puede ser más atrayente para los propios usuarios. Las particularidades del meme, su capacidad de síntesis, la facilidad y velocidad interpretativa que propician en las comunidades de sentido, disputan y aventajan a otros discursos argumentativos como el periodístico. La escasa atención de los usuarios en el marco de la cultura snack, posiciona a los memes, salvando las diferencias argumentales y de desarrollo, en un lugar de preferencia que facilita a los usuarios digitales propuestas interpretativas y valorativas de la realidad social y relega a lugares secundarios a otros textos tradicionales como las columnas de opinión o los editoriales periodísticos.

Finalmente, resulta posible plantear que los memes se posicionan como un discurso social que pone en discusión y marca las debilidades de la propia actividad periodística, que atraviesa de por sí variadas crisis de autoridad. Ciertos valores anacrónicos e inalcanzables ampliamente sostenidos por periodismo liberal y conservador como la objetividad, la imparcialidad, la neutralidad, la independencia de intereses son cuestionados y refutados desde del discurso de ciertos memes. Igualmente, las prácticas periodísticas de construcción 
informativa que privilegian la banalidad, los bizarro o la cobertura de hechos de escaso o nulo interés social son blanco de críticas desde el discurso memético.

\section{Referencias bibliográficas}

Cerezo, P. (2016). Los customer media. Medios líquidos para usuarios hiperconectados. Madrid, España: Evoca.

Clauso, R. (2007). Cómo se construyen las noticias. Los secretos de las técnicas periodísticas. Buenos Aires, Argentina: La Crujía Ediciones.

Danung, J. y Attaway, L. H. (2008). All your media are belong to us: An analysis of the cultural connotations of the internet meme. Literature, Culture and Digital Media, (17).

Dawkins, R. (1976) The Selfish Gene. Oxford, England: Oxford University Press.

Fontcuberta, M. (1993). La noticia. Pistas para percibir el mundo. Barcelona, España: Editorial Paidós.

Fontcuberta, M. y Borrat, H. (2006). Periódicos: sistemas complejos, narradores en interacción. Buenos Aires, Argentina: La Crujía Ediciones.

González Pérez, C. (2019). Memes y lenguaje inclusivo: transformaciones y resistencias. Revista Latinoamericana de Ciencias de la Comunicación (ALAIC), 16 (30), 60-73. Grundlingh, L. (2018). Memes as speech acts. Social Semiotics, 28 (2), 147-168. https://doi.org/10.1080/10350330.2017.1303020 Jenkins, H., Ford, S. y Green, J. (2015). Cultura transmedia. La creación y valor en una cultura en red. Barcelona, España: Editorial Gedisa.

Martini, S. (2000). Periodismo, noticia y noticiabilidad. Buenos Aires, Argentina: Grupo Editorial Norma.

Martini, S. (2017). Últimas noticias. Construyendo la actualidad en el siglo XXI. En Martini, S. y Pereyra, M. (comps.) La noticia hoy. Tensiones entre la política, el mercado y la tecnología. (pp. 1-28) Buenos Aires, Argentina: Ediciones Imago Mundi. 
Noguera Vivo, J. M. (2013). ¿Qué transparencia tienen los periodistas en Twitter? Tendencias hacia un periodismo centrado en el usuario. Revista Comunicación y Sociedad, (26).

Papalini, V. (2010). Hermenéutica crítica: apuntes y reflexiones para la investigación en comunicación. En Arrueta, C., Brunet, M. y Guzmán, J. (eds.) La Comunicación como objeto de estudio (pp. 95-130). San Salvador de Jujuy, Argentina: Ediciones DASS-UCSE.

Pérez Salazar, G., Aguilar Edwards, A., \& Guillermo Archilla, M. E. (2014). El meme en internet: Usos sociales, reinterpretación y significados, a partir de Harlem Shake. Argumentos (México, DF), 27(75), 79-100.

Ricœur, P. (1995). Teoría de la interpretación. México DF, México: Editorial Siglo XXI.

Sánchez Aranda, J. J. (2005). Análisis de contenido cuantitativo de medios. En Berganza Conde, M. y Ruiz San Román, J. (coord.) Investigar en comunicación. Guía práctica de métodos y técnicas de investigación social en comunicación (pp. 207-228). Buenos Aires, Argentina: Mc Graw Hill.

Scolari, C. (2020). Cultura Snack. Ciudad Autónoma de Buenos Aires, Argentina: la marca editora.

Thompson, J. B. (1993). Ideología y cultura moderna. Xochimilco, México: Universidad Autónoma Metropolitana.

Venier, E. (2018). Los memes y la imitación en la socialidad tecnificada. Viator. Revista científica de comunicación desde los bordes, (6), 21-47.

Verón, E. (1996). La semiosis social. Fragmentos de una teoría de la discursividad. Barcelona, España: Editorial Gedisa.

Wiggins, B. E., y Bowers, G. B. (2015). Memes as genre: A structurational analysis of the memescape. New media \& society, 17 (11), 1886-1906. 